\section{KIDS' MASTERPIECES GRACE BDJ}

The cover illustrations on the current volume of the $B D J$ (Volume 215) are the winning entries in a drawing competition run in nursery and primary schools throughout Wales. The schools are participating in the Welsh Government's 'Designed to Smile' oral health improvement programme.

The competition was organised by the Dental Public Health Unit at Cardiff University and the Community Dental Services in Wales. Each issue of the $B D J$ in this volume will feature one of the 12 winners, across four age groups, from the $2,000+$ entries to the competition. The winners and their schools will each receive a substantial contribution to school funds and books courtesy of Nature Publishing Group.

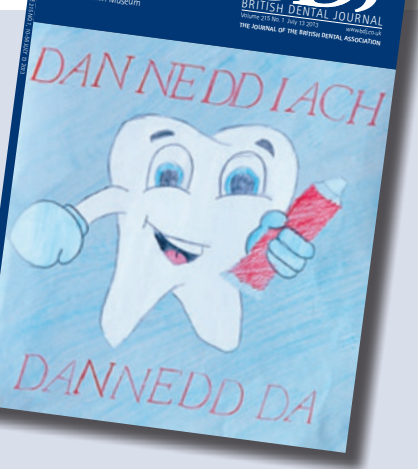

Professor Ivor Chestnutt, Cardiff, said, 'This competition has generated a lot of interest amongst the 78,000 children who participate in the daily in-school toothbrushing programme that is a core element of the Designed to Smile programme. I am very grateful to the British Dental Journal, the Welsh Government and the Community Dental Service who facilitated and organised the competition, and of course, the children, teachers and parents for their enthusiastic participation:

www.designedtosmile.co.uk.

\title{
MORE WENSLEYDALE, GROMIT?
}

Cheese could help prevent caries, according to a study ${ }^{1}$ of plaque $\mathrm{pH}$ after eating dairy products.

A study sample of 12-15-yearolds was asked to refrain from brushing their teeth 48 hours prior to the trial, when baseline plaque $\mathrm{pH}$ was determined at four different tooth sites. The subjects were then randomly assigned to consume cheese, milk, yoghurt or paraffin (control) for three minutes before $\mathrm{pH}$ was tested again at 10, 20 and 30 minutes post-chewing/swishing.
While milk and yoghurt can be considered non-cariogenic, the plaque $\mathrm{pH}$ of those in the cheese group was significantly higher after 30 minutes. A pH value higher than 5.5 lowers the chance of developing cavities and it is theorised that the chewing action from eating cheese increases saliva production, while compounds in the cheese itself may adhere to tooth enamel and further protect teeth from acid.

$$
\begin{aligned}
& \text { 1. Telgi R L, Yadav V, Telgi C R, Boppana N. } \\
& \text { In vivo dental plaque } \mathrm{pH} \text { after consump- } \\
& \text { tion of dairy products. Gen Dent 2013; } \\
& 61: 56-59 \text {. }
\end{aligned}
$$

\section{HONOURS, AWARDS, APPOINTMENTS}

\section{Correction}

In the last issue of the $B D J(214: 611)$ an entry in the Honours, Awards, Appointments column stated that Kristian Davies was shortlisted for the Royal Society of Medicine (odontological section) President's Prize 2013 and was awarded first prize for 'best research project'. This prize was in fact shared with James Darcey.

\section{Chair and Deputy-Chair}

The Dental Faculties have announced the appointments of Mr Trevor Johnson as Chair and Ms Pepe Shirlaw as Deputy-Chair of the MJDF Examination. The new appointees will replace Dr Mike Escudier and Mr Richard Furness, who have played a crucial role over the past three years in the continued development of the MJDF examination as a modern, innovative assessment for today's dentist in primary or secondary care.

\section{GDC Chair}

William 'Bill' Moyes has been appointed as Chair of the GDC, following approval by the Privy Council. Mr Moyes is the first appointed Chair of the GDC and will take up office on 1 October 2013, leading a newly constituted Council, reduced in size from 24 to 12 .

Queen's birthday honours

Dr Susan Greening has been awarded an MBE in the Queen's birthday honours list 2013 for services to dentistry in the UK. Dr Greening is Clinical Director of Gwent Community Dental Service, Aneurin Bevan Health Board.

\section{Welsh Asian Women Award}

Chandrika Joshi, Specialist in Special Care Dentistry, is joint winner of the Welsh Asian Women Achievement Awards in the category of Science, Medicine and Technology. Chandrika was born in Uganda and came to Wales in 1972; she has worked as a senior dental officer for more than 20 years and has dedicated her career to helping people with disabilities.

\section{BDTA President}

Terry Porter has been elected President of the BDTA. Terry is IT Manager at The Dental Directory and has over 30 years of dental trade experience. Mr Porter takes over from Simon Tucker of Medenta Finance.

\section{MUCH-NEEDED NHS PRACTICE OPENS IN SWANAGE}

Barry Cockcroft CBE, the Chief Dental Officer for England, opened a brand new NHS dental practice in Swanage on 14 June 2013. The new practice will bring access to high quality NHS dentistry to over 9,600 people in the Dorset town for the first time in 15 months.

The new practice is run by not-for-profit social enterprise SCA Group, which runs six other NHS Trafalgar dental practices in Hampshire. Following the closure of a previous practice in Swanage, NHS patients have not been able to obtain comprehensive NHS dentistry in the town for 15 months, and have had to travel or use a temporary mobile dental unit.

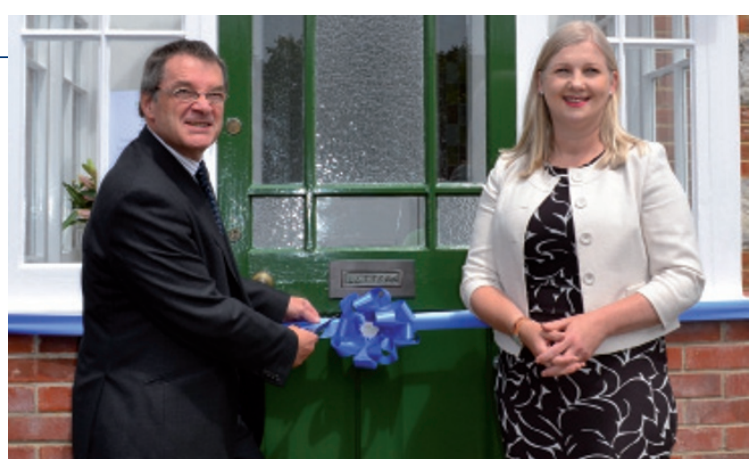

